\title{
Research on Commercial Vehicles Information Service Platform Function Design and Construction Strategy
}

\author{
Shangbin Song ${ }^{1}$, Huimin $\mathrm{Li}^{2}$, Hao $\mathrm{Li}^{3}$ and Libo $\mathrm{Han}^{4}$ \\ Research Institute of Highway Ministry of Transport, Beijing, China
}

\begin{abstract}
Commercial vehicles information service platform has not been constructed in transportation industry yet. It researched about data interaction and information sharing between administrative department, transport enterprises, maintenance enterprises and multiple-function detecting test station of commercial vehicles in this study. It confirms the commercial vehicles information service platform function design and construction strategy, it will supply theory base for design the information service platform, meanwhile it will supply the technical support for road transportation running safely and efficiently.
\end{abstract}

Keywords-commercial vehicles; platform; framework; sharing information; designation

\section{INTRODUCTION}

The commercial vehicles information service platform has not been constructed until now, as a technical method for administrative department to manage the commercial vehicles, it will be an important work to construct the platform.

It will research on commercial vehicles information service platform function design and construction strategy in this study, including the users of the platform, designation, construction strategy and the model of the platform and so on.

\section{USER GROUP}

This platform will be constructed on the base of the platform of the testing and supervision on fuel consumption of road transport vehicles, the number of the users is more, such as the administrative department, transportation management department, the maintenance enterprises, the transportation enterprises, the multiple-function detecting test station, the passenger and cargo terminal and the working staff in road transportation.

\section{REQUIREMENTS ANALYSIS}

This platform will meet the following requirements:

\section{A. Management Requirements}

Administrative department can understand the vehicle development status in time and master the operating status by statistics, query, real-time monitoring and any other ways in this platform. So it can supply the technical support for administrative department in admittance management, process management and exit management. It is also easy for the government to lead the vehicle development and to promote the structure adjustment of road transportation capacity and so on.

\section{B. Operating Requirements}

The user can understand and master the vehicle admittance, register, multiple-function detecting test, operating and maintenance information, and then adjusting vehicle performance requirements and distribution of configuration. This platform can meet data and function requirements for the user group.

\section{FUNCTION DESIGN}

Commercial vehicles information service platform is consist of the following function module:

\section{A. Vehicle Fuel Consumption Admittance Module}

This module is consist of online reporting system for enterprise and inspection report delivery system. For the inspection report, the function contains register online, applying for enterprise, submitting application, statistics, query and so on. For the inspection report delivery system, the function contains the generation of report number, import the report, delivery the report, export the report, delivery the application of modification and so on.

\section{B. Road Transportation Enterprise Safety in Production and} Dynamic Monitoring Integrated Management System

This module is consist of transportation safety production management system and GPS dynamic monitoring system. For the safety production management system, the function is to supply semi-static data, and for the GPS dynamic monitoring system, its function is to supply real-time dynamic data. This module will realize the data interaction to reach the function of the sharing information.

\section{Service for the Industry}

This module is to meet the vehicle information and the distribution of configuration statistics, query and some other function. 


\section{Working Staff in Road Transportation[1]}

This module is to meet working staff in road transportation information query, such as the information of manager of road transportation, drivers, working staff of dangerous cargo transportation, practitioners of motor vehicle maintenance and repair, driver trainer and any other user group.

\section{E. Commercial Vehicle Maintenance Enterprise[2]}

This module is to meet the commercial vehicle information query, and to realize the data interaction between administer department, maintenance enterprise and any other user group.

\section{F. Multiple-Function Detecting Test Station[3]}

This module is to meet the vehicle information query, and to realize the data interaction between the administer department, transportation management department, maintenance enterprise and any other user group.

\section{G. Transportation Management Department}

This module is to meet the commercial vehicle operation certificate management requirements and to realize the data interaction between administer department, multiple-function detecting test station and maintenance enterprise and any other user group.

\section{H. Passenger and Cargo Terminal [4][5]}

This module is to meet commercial vehicle information and transportation enterprise business license information query and to realize the data interaction between administer department, transportation management department, maintenance enterprises, multiple-function detecting test station and any other user group.

\section{CONSTRUCTING STRATEGY}

The commercial vehicle information service platform was construction strategy was built by the following step.

- $\quad$ Researching the data requirements and the function requirements of the administer department, the maintenance enterprises, multiple-function detecting test station and any other user group.

- Making sure the method how to use, filling in, query, statistics and any other function of the commercial vehicle information service platform.

- Getting the data interaction information of the using field, the format and so on of the administer department, the maintenance enterprises, multiplefunction detecting test station and any other user group.

- Demonstrating the commercial vehicle information service platform constructing strategy and adjusting it preliminary.

- $\quad$ Sending this commercial vehicle information service platform function design and construction strategy to the user group, to get the suggestion to make this platform much more consummate.
- Getting the commercial vehicle information service platform module of function design and constructing strategy finally.

\section{CONSTRUCTING MODULE}

After researching and demonstrating of the commercial vehicle information service platform, the work group constructs the module (see FIGURE I), it contains vehicle management of all the stage, internet security and maintenance, laws and regulations, standards and so on.

\section{CONCLUSION}

The commercial vehicle information service platform can supply the technical support and supply the service of data interaction, information sharing, query, statistics and so on for the transportation enterprise, the maintenance enterprise, the transportation management department, multiple-function detecting test station and some other user group. It will be benefit of road transportation industry management and can also lead the commercial vehicles to develop in the direction of professionalization, heavy duty, large scale and then to guarantee transportation safety, green, efficiency.

\section{REFERENCES}

[1] “Working staff in road transportation management regulation,” Ministry of Transport of the People's Republic of China, Nov . 2006.

[2] "Motor vehicle maintenance management regulation," Ministry of Transport of the People's Republic of China, Aug. 2015.

[3] “Commercial vehicle technical management regulation,” Ministry of Transport of the People's Republic of China, Jan. 2006.

[4] “Cargo transportation and terminal management regulation,” Ministry of Transport of the People's Republic of China, May 2012.

[5] "Passenger transportation and terminal management regulation," Ministry of Transport of the People’s Republic of China, Apr. 2016. 


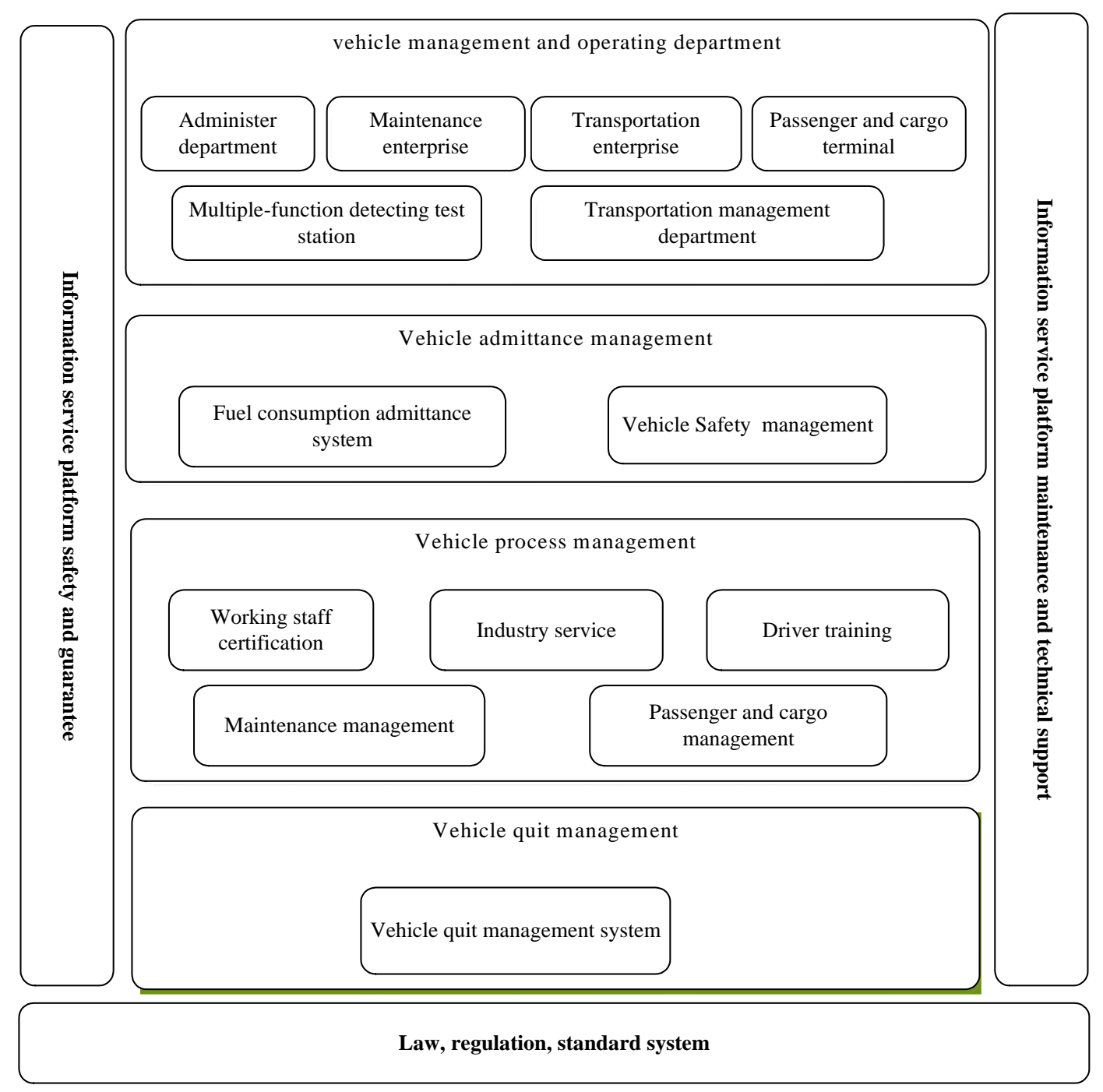

FIGURE I. COMMERcial VeHicle INFORMATION SERVICE PlatForm Model 